\title{
EDITORIAL: \\ FOOD, AGRICULTURE AND BIOTECHNOLOGY TOWARDS SUSTAINABILITY IN THAILAND
}

\author{
VIJITRA LUANG-IN*, SIRIRAT DEESEENTHUM AND ANUCHITA MOONGNGARM
}

Faculty of Technology, Mahasarakham University, Khamriang, Kantarawichai, Maha Sarakham 44150, Thailand.

This special issue is a collection of 17 research papers presented during 'The $7^{\text {th }}$ International Conference on Food, Agriculture and Biotechnology (ICoFAB 2020), held from July 29 to 30, 2020, organized by the Faculty of Technology, Mahasarakham University, Thailand. The issue aims to focus on the present state of science in the three major areas of food technology, agricultural technology and biotechnology towards sustainability in Thailand.

The first theme, food technology, highlights several techniques/methods for enhanced food functionality/physicochemical properties and food management. Three articles address the food boxes packing problems in rectangular container by heuristic method, enrichment of important compound in foods by pulsed vacuum osmotic dehydration and the effects of storage and packaging conditions on physical properties and carotenoid content of mango tablets. One article promotes the use of unripe banana flour for enhanced resistant starch content and food functionality of gluten-free rice cookies. Two articles discuss the use of salinity to enhance melatonin and antioxidant activity in legumes and mungbean sprouts under during seed germination.

The second theme, biotechnology, highlights soil bacterial diversity for agricultural and industrial application, herbal plants used for tea product and ethanol production. Two articles discover soil bacteria with capacity to produce enzymes useful for agriculture to be potentially used as bioinoculant for economic plant growth, and some discovered as halotolerant and halophilic bacteria which are useful for local industrial application. One article promotes a knowledge of using herbal plants to produce heart tonic herbal teas with antioxidant activities. One article presents an orthogonal array design to improve ethanol production from yam bean by thermotolerant yeast Saccharomyces cerevisiae RMU Y-10.

The last theme, agricultural technology, highlights biocontrol, rice field/seed management and fishery sciences. One article discusses the application of powder and essential oil of climbing wedelia, a herbal plant as a biocontrol agent, against maize weevil. One article presents the infrared radiation technology for rice seed quality improvement for sustainable agriculture in Thailand. The other discusses alternate wetting and drying techniques on grain yield and water use efficiency in irrigated rice. Four articles contribute to fisher sciences; the use of trace elements supplementation in low fish meal diets for enhanced growth performance and immune response of white shrimp (Litopenaeus vannamei), the use of papaya peel and baker's yeast supplementation for growth performance of silver barb (Barbonymus gonionotus) and its resistance to Aeromonas hydrophila, the use of different coating material on xylanase and phytase in shrimp feed, and the use of lactic acid and hot water combined treatment for storage quality of shucked hard clam (Meretrix casta).

Special thanks is dedicated to the guest editor members from Faculty of Technology, Mahasarakham University (Assoc. Prof. Dr. Anuchita Moongngarm, Assoc. Prof. Dr. Anut Chantiratikul, Asst. Prof. Dr. Ruchuon Wanna, Asst. Prof. Dr. Eakapol Wangkahart and Asst. Prof. Dr. Vijitra Luang-In) for their professional and exceptional work. For their important contributions, the guest editors would like to sincerely thank all the authors and reviewers. The guest editors are also grateful to Professor 
Dr. Mohd Ikhwanuddin Abdullah (Editor-inChief) and the JSSM production team for their generosity and assistance in making this special issue a reality.

We hope that readers will appreciate this special issue and are able to use the new knowledge from this for their future works towards sustainable development of food, agriculture and biotechnology in their own countries. 